\title{
Open porous morphology evolution in poly (butylene succinate)/chitin nanocrystal nanocomposite foams
}

Hai Fu

Guizhou Normal University

Dexian Yin

Beijing Technology and Business University

Tianhao Wang

Guizhou Normal University

Wei Gong

Guizhou Normal University

Hongfu Zhou ( $\nabla$ zhouhongfu1982@sina.com )

Beijing Technology and Business University https://orcid.org/0000-0001-8487-9769

\section{Research Article}

Keywords: Poly (butylene succinate), Chitin nanocrystals, Foam, Open porous structure, Supercritical CO2

Posted Date: March 8th, 2021

DOI: https://doi.org/10.21203/rs.3.rs-159364/v1

License: (c) (1) This work is licensed under a Creative Commons Attribution 4.0 International License. Read Full License 


\section{Abstract}

In recent decades, biodegradable polymeric open-porous foams have been engaging increasing interests owing to their biodegradability, porosity and biocompatibility. In this work, biodegradable poly (butylene succinate) (PBS)/chitin nanocrystals (ChNCs) nanocomposite foams with open porous structure were successful fabricated by a solid-state batch foaming method. ChNCs were obtained from chitin by using sulfuric acid treatment and then introduced into PBS. The incorporation of ChNCs had a positive effect on the crystallization behaviors, melt viscoelasticity and thermal stability of diverse PBS specimens. Compared with the change of foaming temperature, the addition of ChNCs would cause a prominent influence on the open porous structure of diverse PBS foams. The probable explanation was that during the foaming process, the spherulites and/or ChNCs as the hard region in PBS could be served as pore wall and the amorphous area as the soft region was acted as pore, leading to open porous PBS foams. The reported strategy in this work could provide the guidelines to regulate and control open porous foams in other semi-crystalline polymer matrices.

\section{Introduction}

Microplastics as an emerging pollutant have posed serious threats to natural environment and human health in the past several decades [1,2]. Specifically, microplastics may translocate into human tissues and then trigger human immune response, giving rise to obstruction and inflammation of human organs [3]. They will exist in natural environment for several hundred years, causing profound influence on terrestrial and freshwater environments [4]. As a result, biodegradable polymers have attracted widely increasing attention ranging from academic to industry research owing to their unique biodegradation and compatibility as well as environmental friendliness, which diffusely recognized as potential and effective solution to alleviate the environmental pollution problems of microplastics [5]. In recent years, biodegradable polymers containing poly (lactic acid) (PLA), poly (butylene adipate-co-terephthalate) and poly (butylene succinate) (PBS) displayed great prospects in numerous applications including food packaging and tissue engineering fields.

Among these biodegradable polymers, PBS, synthesized by the polycondensation of succinic acid and 1,4-butanediol, was considered as one of the most promising candidates to substitute traditional petroleum-based polymers because of its controlled biodegradability and outstanding processability [6, 7]. Additionally, PBS displayed high chemical resistance, suitable flexibility and excellent mechanical, which made it widely used in plastic utensils, biomedical industry, mulch films and other related fields [8]. Owing to the outstanding lightweight, thermal insulation and excellent toughness, PBS foam was used extensively in diverse fields including tissue engineering and packaging, which had become a hot-spot research [9].

Special pore structure could endow polymer foams with special functional properties. As one of the most representative pore structures, open porous structure could supply polymer foam with a greater connectivity space and a larger specific surface, which made it applied in solar desalination [10], oil-water 
separation [11, 12], heavy metal ions sorption [13] and tissue engineering [14]. Plenty of techniques have been utilized to prepare open porous polymer foams, including tensile method, phase separation, crosslinking and particle leaching [11-14]. From the perspective of sustainable development, supercritical $\mathrm{CO}_{2}$ $\left(\mathrm{sc}-\mathrm{CO}_{2}\right)$ foaming was considered as a good way to fabricate PBS foams with open porous structure [15].

In recent years, several approaches have been utilized to prepare PBS foams with open porous structure via sc- $\mathrm{CO}_{2}$ foaming $[8,16]$. Yu [8] manufactured an open-pore structured foam by using biodegradable PBS and PLA. It demonstrated that the PLA/PBS interfaces could serve as pore nucleation sites, PBS melt with relative low melt strength contributed to the formation of open cavity. Ju [16] fabricated open porous $\mathrm{PBS} /$ cellulose nanocrystal (CNCs) nanocomposite foams using $\mathrm{sc}^{-} \mathrm{CO}_{2}$ as physical foaming agent. It was found that the addition of CNCs into PBS matrix was beneficial to form open pore structure in PBS foams and significantly improve their in vitro degradation rate.

One of the typical and natural polysaccharides, chitin is known as the second most abundant biomass polymer after cellulose. It is consisted of $\beta(1-4)$-linked $\mathrm{N}$-acetyl-2-amido-2-deoxy-D-glucose units, which could be extracted from diverse living systems such as insect cuticles, crustacean shells, and pore walls of green algae, yeast and fungi [17]. With good biodegradability, biocompatibility, chemical stability and antibacterial activity, chitin as well as its derivatives have been widely utilized in extensive applications including medicine, food, cosmetic and environmental fields [18]. Chitin nanocrystals (ChNCs), obtained from chitin via chemical or physical treatments, are cumulatively considered as a kind of ideal nanofillers

to fabricate functional and environment friendly nanocomposite materials, thanks to their unique rod-like morphology and nanosized dimensions [18]. Nevertheless, to the best of our knowledge, there is no research about preparation of open porous PBS foams with addition of ChNCs by using specific crystalline/amorphous structure as the hard/soft regions.

The purpose of this work was the fabrication of biodegradable PBS/ChNCs foams with good controlled open-pore structure using solid-state batch foaming methods. By control of ChNCs content and foam temperature, this work offered straightforward, effective and environmentally friendly approaches to prepare and tailor gradients of pore size and open porous structure within the porous structure of PBS/ChNCs foams. The modulation of the crystallization and viscoelastic performances of diverse PBS/ChNCs specimens and fine control of foaming temperature allowed the fabrication of open porous $\mathrm{PBS} / \mathrm{ChNCs}$ foams in a wide range of processing conditions, and different pore size, pore density and pore wall (strut) thickness were characterized. This study provided hopeful strategies for developing polymer foams with open porous structure to gain some unique functional properties.

\section{Experimental}

\subsection{Materials}

PBS (HT803S) was provided by Xinjiang Blueridge Tunhe Polyester Co. Ltd. Chitin was obtained by Zhejiang Aoxing Biotechnology Co., Ltd. (China). All other chemicals employed in this research were of 
analytical grade.

\subsection{Preparation of ChNCs}

The ChNCs were prepared using the existing method [19] with some alteration. Briefly, chitin and $\mathrm{H}_{2} \mathrm{SO}_{4}$ aqueous solution ( $3 \mathrm{~mol} / \mathrm{L}$ ) mixed into a flask at the weight ratio of 1:30, using simple magnetic stirring at $95^{\circ} \mathrm{C}$ for $12 \mathrm{~h}$. Whereafter, the suspension was diluted with deionized water and centrifuged, and then the supernatant was decanted. Several times were needed in this process to reach a neutral pH. Finally, the slurry of chitin whisker was lyophilized to acquire ChNCs.

\subsection{Fabrication of various $P B S$ specimens}

Table 1. Experimental formula of different PBS specimens.

\begin{tabular}{|llllll|}
\hline Specimen Name & neat PBS & PBS-ChNCs 0.1 & PBS-ChNCs 0.5 & PBS-ChNCs 1 & PBS-ChNCs 3 \\
PBS (wt.\%) & 100 & 99.9 & 99.5 & 99 & 97 \\
ChNCs (wt.\%) & 0 & 0.1 & 0.5 & 1 & 3 \\
\hline
\end{tabular}

Prior to melt compounding, PBS was dried under $60^{\circ} \mathrm{C}$ for $6 \mathrm{~h}$ in a vacuum to remove any moisture. Diverse PBS-ChNCs specimens at different ratios displayed in Table 1 were prepared via a Haake internal mixer. After, these different blended melts were placed into the required rectangular plate and forced to flow by applying pressure of $10 \mathrm{MPa}$ to prepare cuboid specimens with a thickness of $2 \mathrm{~mm}$ under a certain temperature of $140{ }^{\circ} \mathrm{C}$ and keeping for $5 \mathrm{~min}$.

\subsection{Preparation of diverse PBS foams}

Diverse PBS specimens were foamed in a batch foaming experiments by using $\mathrm{sc}-\mathrm{CO}_{2}$ as physical agent. The specimens were placed into a high-pressure autoclave and were saturated with $\mathrm{CO}_{2}$ at $20 \mathrm{MPa}$ for $6 \mathrm{~h}$ to reach entire saturation. Different foaming temperatures $\left(105,107,109\right.$ and $\left.111^{\circ} \mathrm{C}\right)$ were selected to obtain different foams. After saturated of $6 \mathrm{~h}$, the high-pressure autoclave was quickly depressurized to ordinary pressure at the foaming temperatures aforementioned.

\subsection{Characterizations}

\subsubsection{Fourier transformation infrared spectra (FTIR)}

FTIR spectra of ChNCs were taken on FTIR (IZ10, Thermo, USA) recording within in a spectrometer at stated range resolution $\left(4 \mathrm{~cm}^{-1}\right)$ and wavenumber scope $\left(500-4000 \mathrm{~cm}^{-1}\right)$.

\subsubsection{X-ray diffraction $(X R D)$}

XRD study was performed with an X-ray diffractometer machine (D/max-2500, Rigaku, Japan) by using Cu $\mathrm{K}_{\mathrm{a} 1}(\lambda=0.154056 \mathrm{~nm})$ radiation at a scanning rate of $0.2^{\circ} \mathrm{s}^{-1}$ and scattering range of $5-40^{\circ}$. 
The crystallization capacities of diverse PBS specimens were analyzed with a DSC instrument (Q20, TA, USA). Diverse PBS specimens were first quickly heated to $140^{\circ} \mathrm{C}$ at a heating rate of $10^{\circ} \mathrm{C} / \mathrm{min}$ and kept isothermal for $5 \mathrm{~min}$, then cooled to $40^{\circ} \mathrm{C}$ at a cooling rate of $10{ }^{\circ} \mathrm{C} / \mathrm{min}$ and scanned to $140{ }^{\circ} \mathrm{C}$ again at $10^{\circ} \mathrm{C} / \mathrm{min}$. The crystallinity $\left(\chi_{c}\right)$ of different PBS specimens was determined by Eq. (1): see formula 1 in the supplementary files.

\subsubsection{Transmission electron microscope (TEM)}

The micromorphology of ChNCs was saw by TEM (Talos F200, FEI, USA) at an accelerating voltage of $200 \mathrm{kV}$.

\subsubsection{Polarized Optical Microscope (POM)}

POM (BX51, Olympus, Japan) with a magnification ratio of $400 \times$ was utilized to observe the spherulite morphologies of different PBS specimens. Different PBS specimens were heated rapid to $140{ }^{\circ} \mathrm{C}$, and held for $5 \mathrm{~min}$ to remove heat history, whereafter cooled down to $105^{\circ} \mathrm{C}$ at a heating rate of $30{ }^{\circ} \mathrm{C} / \mathrm{min}$, and subsequently maintained for $40 \mathrm{~min}$ to see the change of spherulite morphology.

\subsubsection{Dynamic rheological performances}

The rheology properties of diverse PBS specimens were tested at $140{ }^{\circ} \mathrm{C}$ by using rotational rheometer (ARES, TA, USA) on a parallel plate (gap of $1 \mathrm{~mm}$ and diameter of $20 \mathrm{~mm}$ ). The angular frequency $(\omega)$ sweep went from 0.1 to $100 \mathrm{rad} \mathrm{s}^{-1}$ within the linear viscoelastic range.

\subsubsection{Thermogravimetric Analysis (TGA)}

The thermal stability of diverse PBS specimens was measured via a TGA apparatus (Q50, TA, USA). Specimens of approximately $6 \mathrm{mg}$ were heated to $700{ }^{\circ} \mathrm{C}$ under nitrogen atmosphere at a rate of 10 ${ }^{\circ} \mathrm{C} / \mathrm{min}$.

\subsubsection{Scanning electron microscopy (SEM)}

The porous structure of diverse PBS foams was observed by SEM (Quanta FEG, FEI, USA). Diverse PBS foams were freeze-fractured in the condition of liquid nitrogen to gain the fractured surface and then coated with Au prior to observation.

\subsubsection{Foaming properties}

The volume expansion ratio (VER) of different PBS foams was measured by equation (2): see formulas 2 and 3 in the supplementary files.

\section{Results And Discussion}




\subsection{Structure and performances of ChNCs}

The FTIR and XRD analysis of ChNCs were shown in Figs. 1a and 1b. Some characteristic peaks of ChNCs could be found in the FTIR of ChNCs. To be specific, adsorption peaks were detected at 1660 and $1558 \mathrm{~cm}^{-1}$ (corresponding to amide I and II of chitin), which confirmed that acid treatment did not change chemical construction of chitin [21]. Two major diffraction peaks of ChNCs at $2 \theta=9.5^{\circ}$ and $19.5^{\circ}$ could be found in Fig. 1(b), which were in accordance with previous research [19]. The broad signal centered at $2 \theta=9.5^{\circ}$ could be associated with glucosamine sequences and the signal $2 \theta=19.5^{\circ}$ occurred owing to $\mathrm{N}$ acetyl-D-glucosamine monomers. In addition, the $\chi_{c}$ of chitin was calculated to be approximately $89.9 \%$. Compared with chitin, the $\chi_{c}$ of ChNCs increased from $89.9 \%$ to $95.8 \%$ (in Fig. 1 b) after acid treatment. The results indicated that sulfuric acid treatment degraded the amorphous region of the chitin and thus improved the $\chi_{c}$ of ChNCs [19]. The SEM and TEM images of ChNCs in Figs. $1 c$ and $1 d$ showed that ChNCs exhibited a rod-like shape, and their lengths and widths were 200-1000 and 10-30 nm, respectively. These results stated above demonstrated the successful sulfuric acid treatment of Chitin.

\subsection{Crystallization and melting properties of PBS nanocomposites}

Crystallization and melting behaviors play a vital role in influencing the processing and foaming performances of semi-crystallization polymers. Spherulites of polymers could not only enhance melt strength as physical entanglements, but also facilitate pore nucleation as heterogeneous nucleation points [22]. The crystallization and melting behaviors of neat PBS and diverse PBS-ChNCs specimens were researched using DSC, and the corresponding data were illustrated in Fig. 2 and Table 2.

Table 2. Thermal performances of different PBS specimens

\begin{tabular}{|lllllll|}
\hline Specimen Name & $\mathrm{T}_{\mathrm{c}}\left({ }^{\circ} \mathrm{C}\right)$ & $\Delta \mathrm{H}_{\mathrm{c}}(\mathrm{J} / \mathrm{g})$ & $\mathrm{T}_{\mathrm{m} 1}\left({ }^{\circ} \mathrm{C}\right)$ & $\mathrm{T}_{\mathrm{m} 2}\left({ }^{\circ} \mathrm{C}\right)$ & $\Delta \mathrm{H}_{\mathrm{m}}(\mathrm{J} / \mathrm{g})$ & $\chi_{\mathrm{c}}(\%)$ \\
\hline neat PBS & 85.7 & 60.5 & 104.2 & 112.8 & 57.2 & 30.3 \\
\hline PBS-ChNCs 0.1 & 85.7 & 62.2 & 103.7 & 112.8 & 58.2 & 31.1 \\
\hline PBS-ChNCs 0.5 & 85.7 & 60.4 & 103.9 & 112.7 & 56.7 & 30.2 \\
\hline PBS-ChNCs 1 & 85.5 & 60.3 & 103.9 & 112.9 & 56.8 & 30.1 \\
\hline PBS-ChNCs 3 & 84.6 & 58.1 & 103.4 & 112.9 & 54.9 & 29.0 \\
\hline
\end{tabular}

As could be seen from DSC data (Fig. 2 and Table 2), neat PBS exhibited the crystallization temperature $\left(T_{C}\right)$ of $85.7^{\circ} \mathrm{C}$ and the $\chi_{C}$ of $30.3 \%$. With the increase of ChNCs content, the $T_{C}$ of diverse PBS-ChNCs specimens slightly shifted to lower values (from 85.7 to $84.6^{\circ} \mathrm{C}$ ) and the $\chi_{c}$ increased firstly after declining. Furthermore, the crystallization and melting enthalpy of diverse PBS-ChNCs specimens was slightly reduced by incorporation of ChNCs (as revealed in Table 2). The results could be made clear by the following two reasons. The first reason was that ChNCs dispersed in PBS matrix could restrict the mobility and arrangement of PBS molecules chains owing to the specific rod-like structure of ChNCs [23, 
24]. The second reason was that the hydrogen bonding interaction formed by ChNCs could also hinder the slippage of PBS molecular chains $[25,26]$. As a result, the crystallization ability of diverse PBS-ChNCs specimens reduced.

As displayed in Fig. 2b, it was clear to observe the double melting peaks containing a low melting temperature $\left(T_{m 1}\right)$ and a relative high melting temperature $\left(T_{m 2}\right)$ in DSC curves of different PBS-ChNCs specimens (Fig. 2b), because of the melt-recrystallization process [20]. To be specific, lots of imperfect lamellae were produced resulting from the heterogeneous nucleation effect of ChNCs addition, which melted at a relative low temperature. Meanwhile, thin lamellae were tended to thicken in the crystallization process, which would melt at a high temperature [20]. The $\mathrm{T}_{\mathrm{m} 1}$ decreased slightly with the increase of ChNCs content, showing that the incorporation of ChNCs led to the formation of imperfect crystals in PBS.

\subsection{POM observations of PBS nanocomposites}

To further study the crystallization behaviors of diverse PBS specimens, the changes in their spherulite morphology and spherulite growth during the isothermal crystallization were investigated by POM. Fig. 3 presented the POM images of different PBS specimens with the same isothermal time $(10 \mathrm{~min})$ at $105^{\circ} \mathrm{C}$. For neat PBS, the spherulite size was relatively large and their number was small owing to that there was adequate space for PBS spherulites to grow before bumping into each other (Fig. 3a) [27]. Nevertheless, with the incorporation of just $0.1 \%$ ChNCs, the number of PBS spherulites improved and accordingly their size was reduced (Fig. 3b). In addition, more and smaller spherulites were obtained in diverse PBS-ChNCs specimens with ChNCs content further increasing. It was owing to that more spherulites formed at higher temperatures and earlier times owing to the existence of heterogeneous surfaces [27, 28]. The spherulites collided with each other at smaller size and hinder each other growth [29]. It was quite evident that neat PBS crystallized with a representative homogeneous nucleation, while the crystallization of diverse PBSChNCs specimens happened through not only the homogeneous nucleation but also heterogeneous nucleation contributed by nanofillers, lessening the crystallization induction period and increasing the nucleation density of PBS. It could be found clearly in Fig. 3 that PBS displayed a soft area in the amorphous region and a hard area in the spherulite region. To fabricate open porous PBS foams, the hard/soft inhomogeneity strategy was expected to extend to crystalline/amorphous structure.

\subsection{Rheological properties of PBS nanocomposites}

The foamability of polymers relatively depended on their viscoelastic properties [30], which could be investigated by the storage modulus ( $\left.G^{\prime}\right)$ (elastic contribution), the complex viscosity ( $\left.\eta^{\star}\right)$ (viscous contribution), $\tan \delta$ and Cole-Cole plots during rheology measurements. Fig. 4 displayed the dependence of $\mathrm{G}^{\prime}, \eta^{\star}, \tan \delta$ and Cole-Cole plots for different PBS specimens at $140{ }^{\circ} \mathrm{C}$.

The G' of diverse PBS specimens as a function of $\omega$ was shown in Fig. 4a. It was apparent in Fig. 4a that the $G^{\prime}$ of different PBS specimens increased in the range of $\omega$, due to the representative melt elastic performances of polymers [30]. Besides that, the G' of PBS-ChNCs 0.1 were higher than that of neat PBS, 
and ChNCs loading rising caused a gradual increase in G' of different PBS specimens. This behavior could be attributed to the hydrogen bonding interaction and the stiffness imparted by ChNCs that allowed efficient stress transfer, which enhanced the G' of PBS $[25,26,31]$.

Fig. $4 \mathrm{~b}$ displayed the $\eta^{*}$ of diverse PBS specimens in the rheological tests. As displayed in Fig. $4 \mathrm{~b}$, the $\eta^{*}$ of all PBS specimens decreased with increasing $\omega$, indicating the shear thinning performance of polymers, which may be ascribed to the orientation of the molecular chains that applied a shearing force [20]. Distinctly, the $\eta^{*}$ of different PBS specimens improved by increasing ChNCs content into PBS matrix, probably originating from the structure of ChNCs. The presence of ChNCs perturbed the flow of PBS melts and hindered the mobility of PBS chain segments [31,32]. Therefore, the higher the amount of ChNCs, the worse was the dispersion of the minor phase in PBS melt and the higher was the viscosity of diverse PBS-ChNCs specimens.

Tan $\delta$, equivalent to loss modulus (G")/G', considered as an important analysis criterion to reflect the melt viscoelastic properties of polymer [28]. According to the viscoelastic theory of polymer, it exhibited a liquid-like behavior when G" was higher than G', over the left, it displayed a solid-like performance [33, 34]. The effect of ChNCs on the rheological property of diverse PBS-ChNCs specimens could be seen by their $\tan \delta$ results, which was displayed in Fig. 4c. For all PBS specimens, the decrease trend of $\tan \delta$ could be seen with increasing CNTs content and their tan $\delta$ values were higher than 1, displaying liquid-like behaviors. It indicated that diverse PBS specimens exhibited fast elastic response and ameliorated foamability with the incorporation of ChNCs [20].

Cole-Cole plots consisting of a real and an imaginary part of the complex viscosity was utilized to reflect the viscoelastic performances of diverse PBS specimens [35]. The Cole-Cole plots should be a perfect semicircle if the relaxation behavior of diverse PBS specimens could be described by a single relaxation time [36]. It was observed in Fig. 4d that diverse PBS specimens displayed perfect semicircle curves with similar characteristic shapes, implying the similar relaxation mechanisms of diverse PBS specimens. With the increasing of ChNCs contents, the arc of the semicircle curve became wider and larger, indicating that the incorporation of ChNCs improved the viscoelasticity and melt strength of different PBS specimens $[36,37]$.

\subsection{TGA Analyses of PBS nanocomposites}

TGA could record the decrease of specimen weight according to increase temperature in the form of programmed heating [9]. Therefore, the thermal decomposition and thermal stability of different PBS specimens were investigated via TGA. Fig. 5 exhibited the TGA curves of diverse PBS specimens and their thermal data were listed in Table 3.

It could be found in Table 3 that the initial degradation temperature $\left(T_{-5}\right)$ of neat PBS was $344.2^{\circ} \mathrm{C}$. The $\mathrm{T}_{-5}$ of different PBS-ChNCs specimens was improved after the addition of ChNCs. With the content of ChNCs increased from 0.1 to $3 \mathrm{wt} . \%$, the $\mathrm{T}_{-5}$ of diverse PBS-ChNCs specimens increased slightly from 345.7 to $353.8^{\circ} \mathrm{C}$ and the temperature rising tendency of the $T_{-50}$ was unaffected in diverse PBS-ChNCs 
specimens. This was probably owing to the generation of hydrogen bonds between ChNCs and PBS matrix [25]. The existence of hydrogen bonds caused a restriction in the movement of PBS chains and led to the formation of a more compact structure in diverse PBS-ChNCs specimens, which would contribute to the suppression of the decomposition of PBS $[25,26]$. In addition, char residue of diverse PBS-ChNCs specimens increased from $1.86 \%$ to $3.26 \%$ with ChNCs content increased from 0.1 to 3 wt. \%, probably because ChNCs acted as an additional carbon source for char formation.

Table 3. TGA thermogram of diverse PBS specimens under nitrogen atmosphere.

\begin{tabular}{|lcccl|}
\hline Specimen Name & $\mathrm{T}_{-5}\left({ }^{\circ} \mathrm{C}\right)$ & $\mathrm{T}_{-10}\left({ }^{\circ} \mathrm{C}\right)$ & $\mathrm{T}_{-50}\left({ }^{\circ} \mathrm{C}\right)$ & Char residue (\%) at $630{ }^{\circ} \mathrm{C}$ \\
\hline neat PBS & 344.2 & 354.9 & 387.7 & 1.86 \\
\hline PBS-ChNCs 0.1 & 345.7 & 356.0 & 388.6 & 2.28 \\
\hline PBS-ChNCs 0.5 & 347.9 & 358.3 & 392.5 & 2.39 \\
\hline PBS-ChNCs 1 & 349.3 & 360.9 & 393.8 & 2.45 \\
\hline PBS-ChNCs 3 & 353.8 & 365.3 & 394.9 & 2.72 \\
\hline
\end{tabular}

\subsection{Foaming behaviors of PBS nanocomposites}

Figs. 6 and 7 exhibited the porous morphologies and pore size distribution of different PBS foams, and the foaming parameters containing pore size, pore density, VER and pore wall (strut) thickness were listed in Table 4.

For neat PBS, linear PBS molecular chains and relatively low molecular weight decided its poor melt strength $[20,38]$. Hence, pores coalesced and ruptured in its foaming process, producing unsatisfactory porous morphology in Fig. 6a, such as oval and coalescent porous structures as well as thin pore strut. Owing to the enhanced melt strength and viscoelasticity of different PBS specimens by adding ChNCs, ameliorative porous morphologies of different PBS-ChNCs foams could be found in the SEM micrographs (Fig. 6) and the pore size of diverse PBS-ChNCs foams decreased gradually, as listed in Table 4. It was because that the ChNCs in PBS resulted in an increment in the number of tiny spherulites in different PBS-ChNCs specimens (as shown in Fig. 3), which enhanced the $\eta^{*}$ and raised the number of pore nucleation points by heterogeneous pore nucleation $[9,28]$. As a result, the pore size of diverse PBSChNCs foams decreased from 17.1 to $7.3 \mu \mathrm{m}$. It could also be found in Table 4 that the increment of ChNCs addition in PBS matrix brought about a gradual increase in pore density (from $0.61 \times 10^{9}$ to $1.1 \times 10^{9}$ pores $\left.\mathrm{cm}^{-3}\right)$, attributing to the addition of ChNCs and their heterogeneous pore nucleation effects $[20,39]$. In addition, the pore size distribution of different PBS foams became narrow with the increase of ChNCs content, which implied the pore size became uniform in diverse PBS-ChNCs specimens.

It was interesting to notice that the pore wall (strut) thickness of diverse PBS-ChNCs foams decreased with the increase of ChNCs content, which could be interpreted as the increment of tiny spherulites in 
PBS. The hard region in the spherulites could be saved as pore wall (strut) and the soft region in the amorphous area was acted as pore, and the soft region contributed to the formation of pore connection channels. With the ChNCs content in PBS matrix increased from 0 to $0.5 \mathrm{wt} . \%$, the pore strut thickens gradually (from 3.1 to $5.8 \mu \mathrm{m}$ ). When the content of ChNCs further increased (1 or $3 \mathrm{wt} . \%$ ), the morphology of pore strut in diverse PBS foams occurred a qualitative difference, that was, pore strut changed into pore wall (displayed in Fig. 6).

Table 4. Foaming parameters of different PBS foams at $111^{\circ} \mathrm{C}$.

\begin{tabular}{|c|c|c|c|c|c|}
\hline Specimen Name & $\begin{array}{l}\text { neat } \\
\text { PBS }\end{array}$ & $\begin{array}{l}\text { PBS-ChNCs } \\
0.1\end{array}$ & $\begin{array}{l}\text { PBS-ChNCs } \\
0.5\end{array}$ & $\begin{array}{l}\text { PBS-ChNCs } \\
1\end{array}$ & $\begin{array}{l}\text { PBS-ChNCs } \\
3\end{array}$ \\
\hline Pore size $(\mu \mathrm{m})$ & 17.1 & 13.7 & 11.9 & 8.3 & 7.3 \\
\hline $\begin{array}{l}\text { Pore density }\left(10^{9} \text { pores }\right. \\
\left.\mathrm{cm}^{-3}\right)\end{array}$ & 0.61 & 0.68 & 0.71 & 0.80 & 1.10 \\
\hline VER & 7.14 & 5.77 & 3.46 & 3.40 & 3.22 \\
\hline $\begin{array}{l}\text { Pore wall (strut) thickness } \\
(\mu \mathrm{m})\end{array}$ & 3.1 & 5.2 & 5.8 & 7.6 & 9.1 \\
\hline
\end{tabular}

Table 5. Foaming parameters of PBS-ChNCs 0.5 foams at diverse foaming temperatures.

\begin{tabular}{|lllll|}
\hline Foaming temperature $\left({ }^{\circ} \mathrm{C}\right)$ & 105 & 107 & 109 & 111 \\
\hline Pore size $(\mu \mathrm{m})$ & 9.8 & 10.4 & 11.6 & 11.9 \\
\hline Pore density $\left(10^{9}\right.$ pores $\left.\mathrm{cm}^{-3}\right)$ & 1.18 & 0.98 & 0.77 & 0.71 \\
\hline VER & 4.85 & 4.60 & 3.86 & 3.46 \\
\hline Pore wall $($ strut $)$ thickness $(\mu \mathrm{m})$ & 7.6 & 6.9 & 5.1 & 4.6 \\
\hline
\end{tabular}

Foaming temperatures, a crucial element in polymer foaming processes, could significantly influence the viscoelasticity and melt strength of polymers as well as pore structure of their foams [40]. Hence, different foaming temperatures were selected to research the open porous foaming behavior of PBSChNCs 0.5 specimen. The porous morphologies and pore size distribution of different PBS foams were presented in Figs. 8 and 9, and the foaming parameters were listed in Table 5. Moreover, the change of foaming temperature had no significant effects on the pore size distribution of diverse PBS foams (as presented in Fig. 9).

It could be observed in Table 5 that the increase in foaming temperature would bring about slight increment in the pore size of PBS foams, decrement of their pore density and a downward trend of their VER. When the foaming temperature went up from 105 to $111^{\circ} \mathrm{C}$, melt strength and melt viscoelasticity decreased and some spherulites liquated, which generated the pore coalescence of PBS foams [9]. The 
change of pore density and pore size indicated that both melt strength and melt viscoelasticity could affect the foaming process of PBS. Particularly, the pore wall of PBS foams became gradual thin with the increase of foaming temperature, and finally changed into pore strut. The decreased pore wall (strut) thickness implied that the specific crystalline/amorphous structure caused a prominent effect on the open pore structure of diverse PBS-ChNCs foams.

\subsection{Foaming mechanism}

Fig. 10 displayed the schematic diagram for the open porous morphology evolution of diverse PBS foams. It could be found in Fig. 10 that both ChNCs addition and foaming temperature changing would influence the porous morphology of diverse PBS foams, especially the pore wall (strut) thickness and open porous structure. During the foaming process, the spherulites and/or ChNCs as the hard region formed pore wall (strut) and the amorphous area as the soft region developed pore, which were called as the specific crystalline/amorphous structure. Open porous structure was formed in PBS due to that the soft region contributed to the formation of pore connection channels. The incorporation of ChNCs in PBS could facilitate the heterogeneous nucleation effects and increase the number of tiny spherulites in PBS. As a result, the area of hard region increased, leading to the pore wall (strut) thickening. When the foaming temperature increased, some spherulites in PBS liquated and the melt viscoelasticity of PBS decreased, leading to the decline of hard region and thus thinned the pore wall of diverse PBS foams.

\section{Conclusions}

In this paper, straightforward, effective and environmentally friendly strategies were presented to prepare biodegradable PBS foams with open porous structure by introducing ChNCs as bionanofillers based on solid-state $\mathrm{sc}-\mathrm{CO}_{2}$ foaming methods. FTIR, XRD and TEM results demonstrated the successful sulfuric acid treatment of Chitin to produce ChNCs. The consequences of DSC and POM manifested that ChNCs could be served as heterogeneous nucleating agent to improve crystallization behaviors of PBS. At the same time, the introduction of ChNCs facilitated the melt strength and melt viscoelasticity of diverse PBS specimens, which could also ameliorate the porous structure of diverse PBS foams. ChNCs content and foaming temperature had significant influences on the porous morphology of diverse PBS foams. Specifically, with ChNCs content increased from 0 to $3 \mathrm{wt}$ \%, pore strut changed from thin to thick, and finally changed into pore wall. However, this variation exhibited a contrary rule when increase the foaming temperature in the foaming process. The likely formation mechanism for the open porous PBS/ChNCs nanocomposite foams was that the spherulites and/or ChNCs as hard region in PBS could be saved as pore wall and the amorphous area as soft region was acted as pore, and open porous structure was formed because the soft region contributed to the formation of pore connection channels. This study states the guidelines to regulate and control open porous polymer foams via introducing nanofillers and changing foaming temperatures.

\section{Declarations}




\section{Acknowledgements}

The authors would like to acknowledge financial support by National Natural Science Foundation of China (No. 21764004), Guizhou Provincial Science and Technology Foundation (No. [2016]1100), Youth science and technology talent growth of Guizhou Province Education Department (KY [2016]136), the Scientific Research Starting Fund for Doctoral Program at Guizhou Normal University (2014), and Open Research Fund support by Key laboratory of Processing and Quality Evaluation Technology of Green Plastics of China National Light Industry Council (BS201708).

\section{Conflict of interest}

The authors declare that they have no conflict of interest.

\section{References}

1. Cox KD, Covernton GA, Davies HL et al (2019) Human consumption of microplastics. Environ Sci Technol 53(12):7068-7074. https://doi.org/10.1021/acs.est.9b01517

2. Silva-Cavalcanti JS, Silva JDB, Franca EJd et al (2017) Microplastics ingestion by a common tropical freshwater fishing resource. Environ Pollut 221:218-226. https://doi.org/10.1016/j.envpol.2016.11.068

3. Prata JC (2018) Airborne microplastics: Consequences to human health? Environ Pollut 234:115126. https://doi.org/10.1016/j.envpol.2017.11.043

4. Laskar N, Kumar U (2019) Plastics and microplastics: A threat to environment. Environ Technol Inno 14:100352. https://doi.org/10.1016/j.eti.2019.100352

5. Kalimuthu M, Nagarajan R, Batcha AA et al (2019) Mechanical property and morphological analysis of polyester composites reinforced with cyperus pangorei fibers. J Bionic Eng 16(1):164-174. https://doi.org/10.1007/s42235-019-0015-6

6. Kuang T, Ju J, Yang Z et al (2018) A facile approach towards fabrication of lightweight biodegradable poly (butylene succinate)/carbon fiber composite foams with high electrical conductivity and strength. Compos Sci Technol 159:171-179. https://doi.org/10.1016/j.compscitech.2018.02.021

7. Ru K, Zhang S, Peng X et al (2019) Fabrication of poly (butylene succinate) phosphorus-containing ionomers microcellular foams with significantly improved thermal conductivity and compressive strength. Polymer 185:121967. https://doi.org/10.1016/j.polymer.2019.121967

8. Yu P, Mi HY, Huang A et al (2015) Effect of poly (butylenes succinate) on poly (lactic acid) foaming behavior: Formation of open cell structure. Ind Eng Chem Res 54(23):6199-6207. https://doi.org/10.1021/acs.iecr.5b00477

9. Yin D, Mi J, Zhou H et al (2019) Microcellular foaming behaviors of chain extended poly (butylene succinate)/polyhedral oligomeric silsesquioxane composite induced by isothermal crystallization. Polym Degrad Stabil 167:228-240. https://doi.org/10.1016/j.polymdegradstab.2019.07.010 
10. He S, Chen C, Kuang Y et al (2019) Nature-inspired salt resistant bimodal porous solar evaporator for efficient and stable water desalination. Energ Environ Sci 12(5):1558-1567. https://doi.org/10.1039/c9ee00945k

11. Wang $Y$, Yang $H$, Chen $Z$ et al (2018) Recyclable oil-absorption foams via secondary phase separation. ACS Sustain Chem Eng 6(11):13834-13843. https://doi.org/10.1021/acssuschemeng.8b01950

12. Liu Y, Huang G, Gao C et al (2015) Biodegradable polylactic acid porous monoliths as effective oil sorbents. Compos Sci Technol 118:9-15. https://doi.org/10.1016/j.compscitech.2015.08.005

13. Li X, Li Y, Zhang S, Ye Z (2012) Preparation and characterization of new foam adsorbents of poly (vinyl alcohol)/chitosan composites and their removal for dye and heavy metal from aqueous solution. Chem Eng J 183:88-97. https://doi.org/10.1016/j.cej.2011.12.025

14. Nishida Y, Domura R, Sakai R et al (2015) Fabrication of PLLA/HA composite scaffolds modified by DNA. Polymer 56:73-81. https://doi.org/10.1016/j.polymer.2014.09.063

15. Hou J, Jiang J, Guo H et al (2020) Fabrication of fibrillated and interconnected porous poly ( $\varepsilon$ caprolactone) vascular tissue engineering scaffolds by microcellular foaming and polymer leaching. RSC Adv 10(17):10055-10066. https://doi.org/10.1039/d0ra00956c

16. Ju J, Gu Z, Liu X et al (2020) Fabrication of bimodal open-porous poly (butylene succinate)/cellulose nanocrystals composite scaffolds for tissue engineering application. Int J Biol Macromol 147:11641173. https://doi.org/10.1016/j.ijbiomac.2019.10.085

17. Salaberria AM, Teruel-Juanes R, Badia JD et al (2018) Influence of chitin nanocrystals on the dielectric behaviour and conductivity of chitosan-based bionanocomposites. Compos Sci Technol 167:323-330. https://doi.org/10.1016/j.compscitech.2018.08.019

18. Wu C, Li Y, Sun J et al (2020) Novel konjac glucomannan films with oxidized chitin nanocrystals immobilized red cabbage anthocyanins for intelligent food packaging. Food Hydrocolloids 98:105245. https://doi.org/10.1016/j.foodhyd.2019.105245

19. Ji N, Liu C, Zhang S et al (2017) Effects of chitin nano-whiskers on the gelatinization and retrogradation of maize and potato starches. Food Chem 214:543-549.

https://doi.org/10.1016/j.foodchem.2016.07.113

20. Yin D, Mi J, Zhou H et al (2020) Fabrication of branching poly (butylene succinate)/cellulose nanocrystal foams with exceptional thermal insulation. Carbohydr Polym 247:116708. https://doi.org/10.1016/j.carbpol.2020.116708

21. Huang Y, Zhang L, Yang J et al (2013) Structure and properties of cellulose films reinforced by chitin whiskers. Macromol Mater Eng 298(3):303-310. https://doi.org/10.1002/mame.201200011

22. Zhao B, Zhao C, Wang C, Park CB (2018) Poly (vinylidene fluoride) foams: A promising low-k dielectric and heat-insulating material. J Mater Chem C 6(12):3065-3073. https://doi.org/10.1039/c8tc00547h

23. Mukherjee T, Czaka M, Kao N et al (2014) Dispersion study of nanofibrillated cellulose based poly (butylene adipate-co-terephthalate) composites. Carbohydr Polym 102:537-542. 
https://doi.org/10.1016/j.carbpol.2013.11.047

24. Shi K, Liu Y, Hu X et al (2018) Preparation, characterization, and biodegradation of poly (butylene succinate)/cellulose triacetate blends. Int J Biol Macromol 114:373-380. https://doi.org/10.1016/j.jjbiomac.2018.03.151

25. Voronova MI, Surov OV, Guseinov SS (2015) Thermal stability of polyvinyl alcohol/nanocrystalline cellulose composites. Carbohydr Polym 130:440-447. https://doi.org/10.1016/j.carbpol.2015.05.032

26. Wang Z, Qiao X, Sun K (2018) Rice straw cellulose nanofibrils reinforced poly (vinyl alcohol) composite films. Carbohydr Polym 197:442-450. https://doi.org/10.1016/j.carbpol.2018.06.025

27. Ten E, Jiang L, Wolcott MP (2012) Crystallization kinetics of poly (3-hydroxybutyrate-co-3hydroxyvalerate)/cellulose nanowhiskers composites. Carbohydr Polym 90(1):541-550. https://doi.org/10.1016/j.carbpol.2012.05.076

28. Li Y, Zhou H, Wen B (2019) A facile and efficient method for preparing chain extended poly (lactic acid) foams with high volume expansion ratio. J Polym Environ 28(1):17-31. https://doi.org/10.1007/s10924-019-01572-2

29. Myoung SH, Im SS, Kim SH (2016) Non-isothermal crystallization behavior of PLA/acetylated cellulose nanocrystal/silica nanocomposites. Polym Int 65(1):115-124. https://doi.org/10.1002/pi.5038

30. Wang G, Zhao J, Mark LH et al (2017) Ultra-tough and super thermal-insulation nanocellular PMMA/TPU. Chem Eng J 325:632-646. https://doi.org/10.1016/j.cej.2017.05.116

31. Kiziltas A, Nazari B, Gardner DJ, Bousfield DW (2014) Polyamide 6-cellulose composites: Effect of cellulose composition on melt rheology and crystallization behavior. Polym Eng Sci 54(4):739-746. https://doi.org/10.1002/pen.23603

32. Wang JM, Ding SJ, Wu TM (2020) Rheology, crystallization behavior, and mechanical properties of poly (butylene succinate-co-terephthalate)/cellulose nanocrystal composites. Polym Test 87:106551. https://doi.org/10.1016/j.polymertesting.2020.106551

33. Correa JP, Bacigalupe A, Maggi J, Eisenberg P (2016) Biodegradable PLA/PBAT/clay nanocomposites: Morphological, rheological and thermomechanical behavior. J Renew Mater 4(4):258-265. https://doi.org/10.7569/jrm.2016.634117

34. Hu X, Lu Y, Li M et al (2018) Effect of montmorillonite on the crystallization, rheological and physical behavior of polyamide-6/polylactic acid blends. Polym Sci Ser A 60(2):229-238. https://doi.org/10.1134/s0965545x18020062

35. Nikolic MS, Petrovic R, Veljovic D et al (2017) Effect of sepiolite organomodification on the performance of PCL/sepiolite nanocomposites. Eur Polym J 97:198-209. https://doi.org/10.1016/j.eurpolymj.2017.10.010

36. Singla RK, Zafar MT, Maiti SN, Ghosh AK (2017) Physical blends of PLA with high vinyl acetate containing EVA and their rheological, thermo-mechanical and morphological responses. Polym Test 63:398-406. https://doi.org/10.1016/j.polymertesting.2017.08.042 
37. Bhattacharjee SK, Chakraborty G, Kashyap SP et al (2020) Study of the thermal, mechanical and melt rheological properties of rice straw filled poly (butylene succinate) bio-composites through reactive extrusion process. J Polym Environ https://doi.org/10.1007/s10924-020-01973-8

38. Wang X, Li Y, Jiao Y (2019) Microcellular foaming behaviors of poly (lactic acid)/low-density polyethylene blends induced by compatibilization effect. J Polym Environ 27(8):1721-1734. https://doi.org/10.1007/s10924-019-01466-3

39. Huang P, Wu F, Pang $Y$ et al (2019) Enhanced dispersion, flame retardancy and mechanical properties of polypropylene/intumescent flame retardant composites via supercritical $\mathrm{CO}_{2}$ foaming followed by defoaming. Compos Sci Technol 171:282-290. https://doi.org/10.1016/j.compscitech.2018.12.029

40. Kuang T, Chen F, Chang $L$ et al (2017) Facile preparation of open-cellular porous poly (-lactic acid) scaffold by supercritical carbon dioxide foaming for potential tissue engineering applications. Chem Eng J 307:1017-1025. https://doi.org/10.1016/j.cej.2016.09.023

\section{Figures}
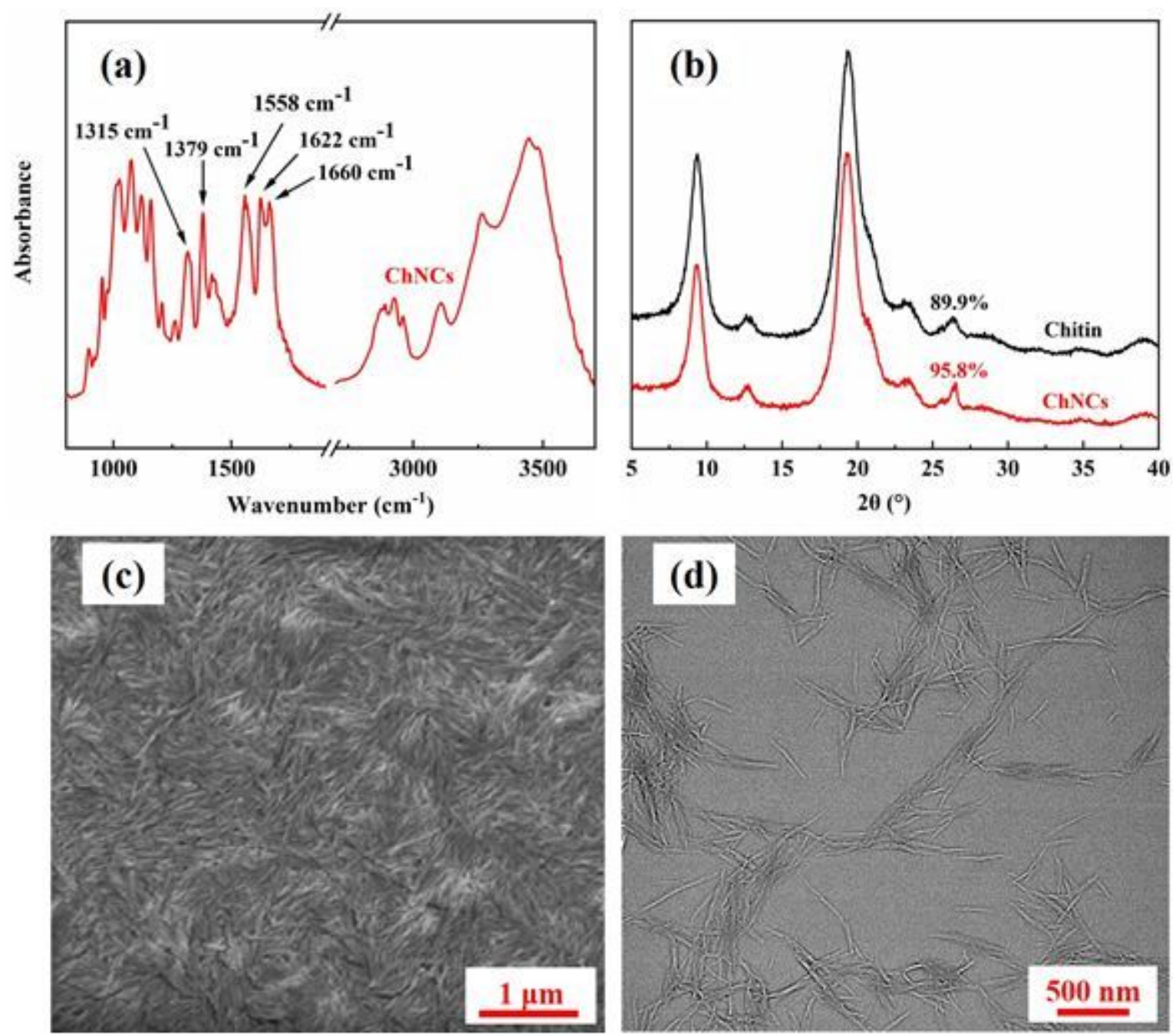

Figure 1 
(a) FTIR spectra, (b) XRD patterns, (c) SEM images and (d) TEM images of ChNCs.
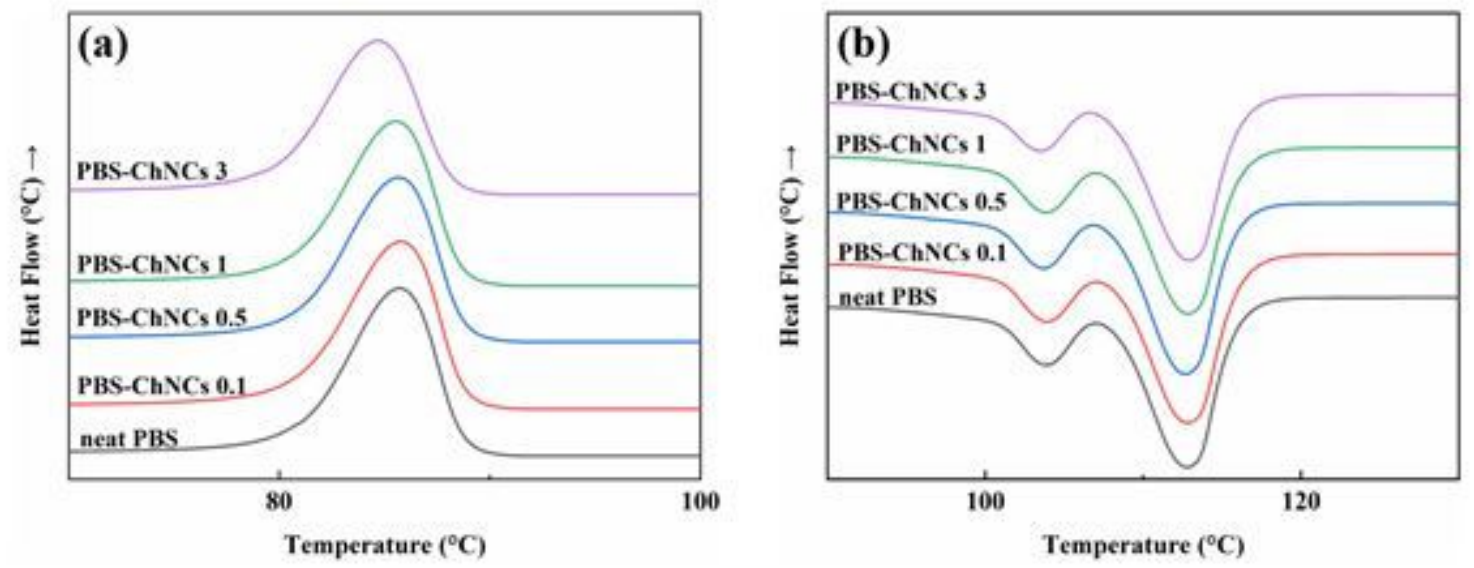

Figure 2

DSC curves ((a) cooling curves; (b) heating curves) of different PBS specimens.

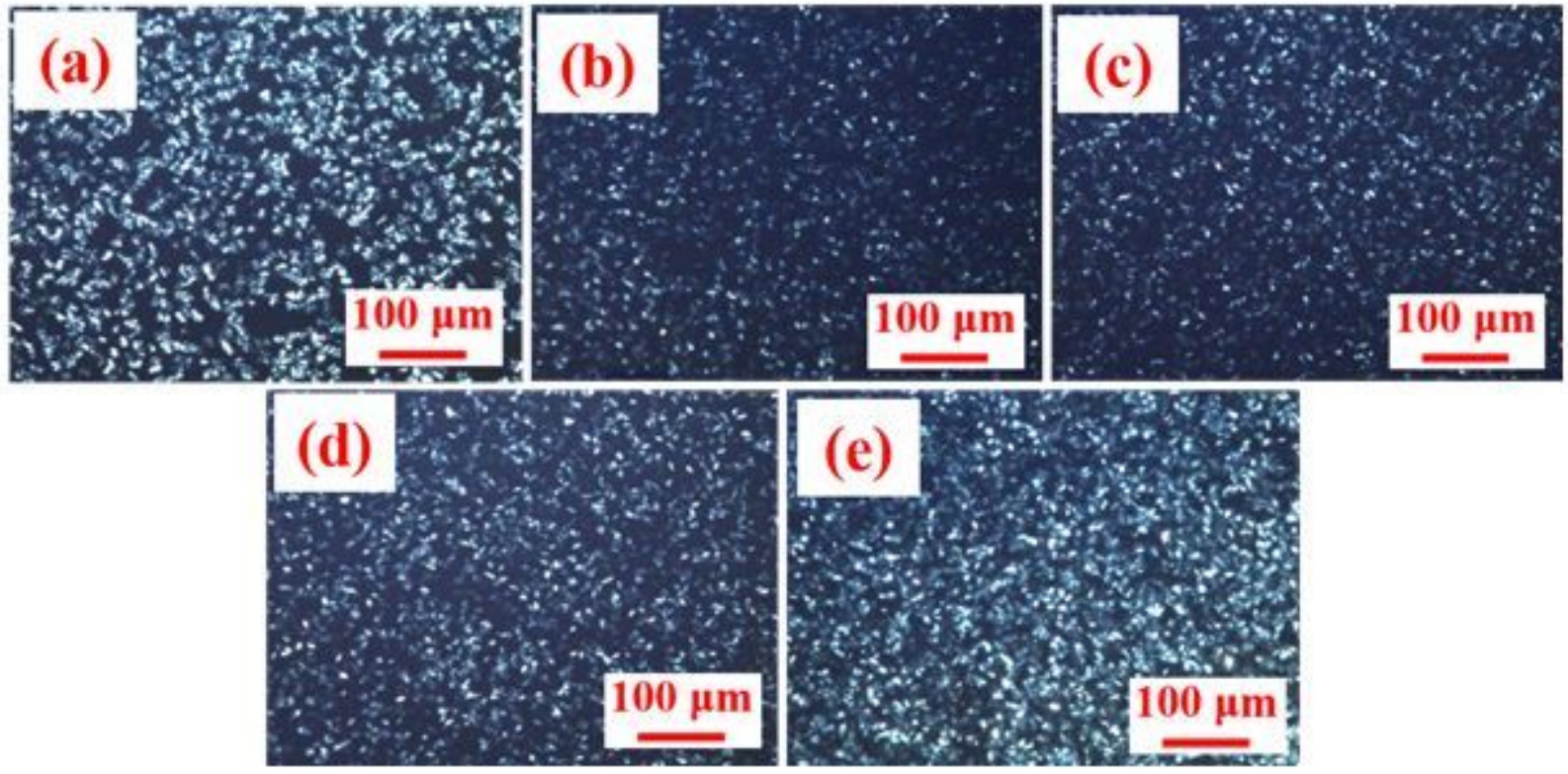

Figure 3

POM photographs of different PBS specimens isothermally crystallized at $105^{\circ} \mathrm{C}$ for 10 min): (a) neat PBS; (b) PBS-ChNCs 0.1; (c) PBS-ChNCs 0.5; (d) PBS-ChNCs 1; (e) PBS-ChNCs 3; 

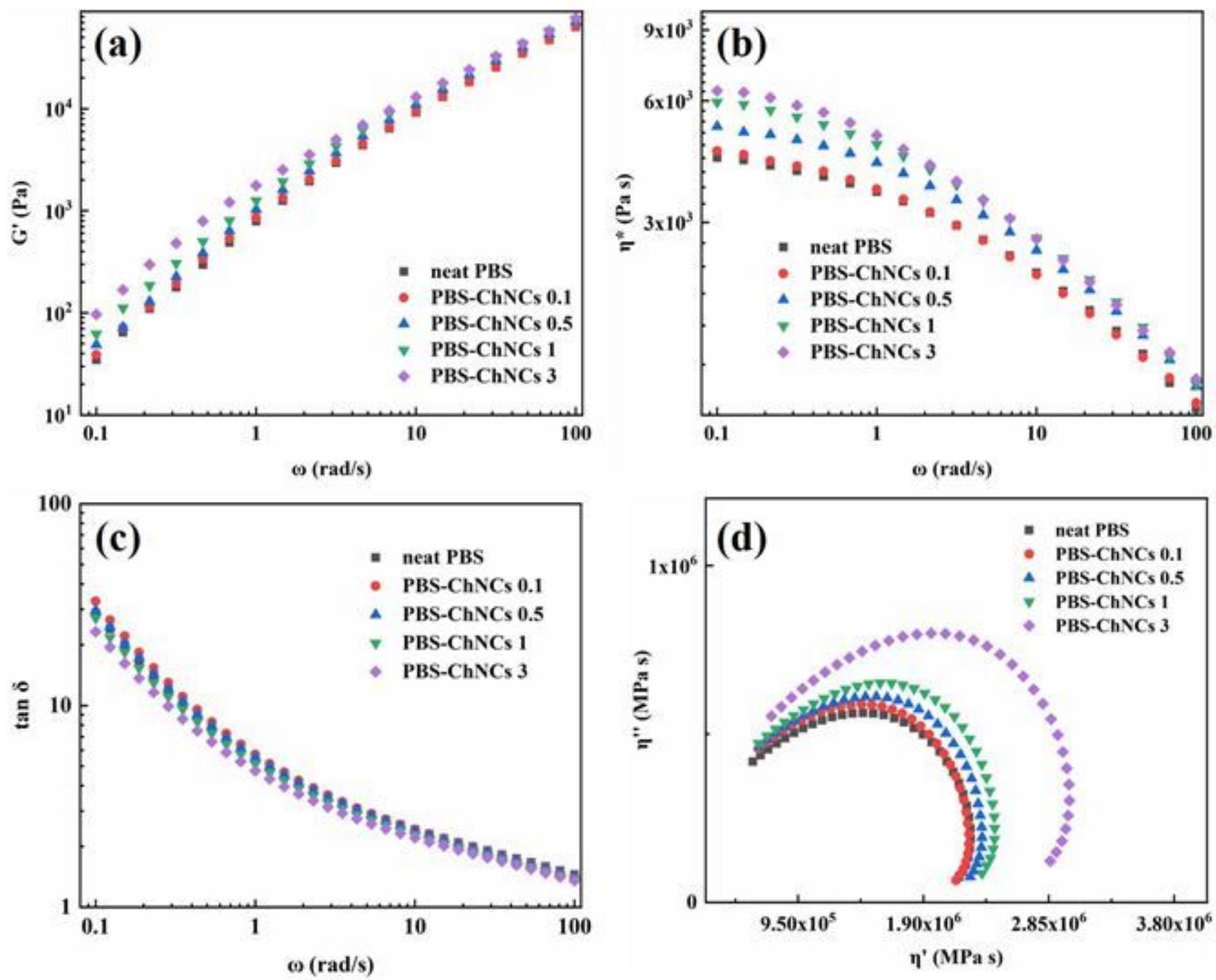

Figure 4

Rheology performances of diverse PBS specimens: (a) G'; (b) $\eta^{*}$; (c) tan $\delta$; (d) Cole-Cole plots. 


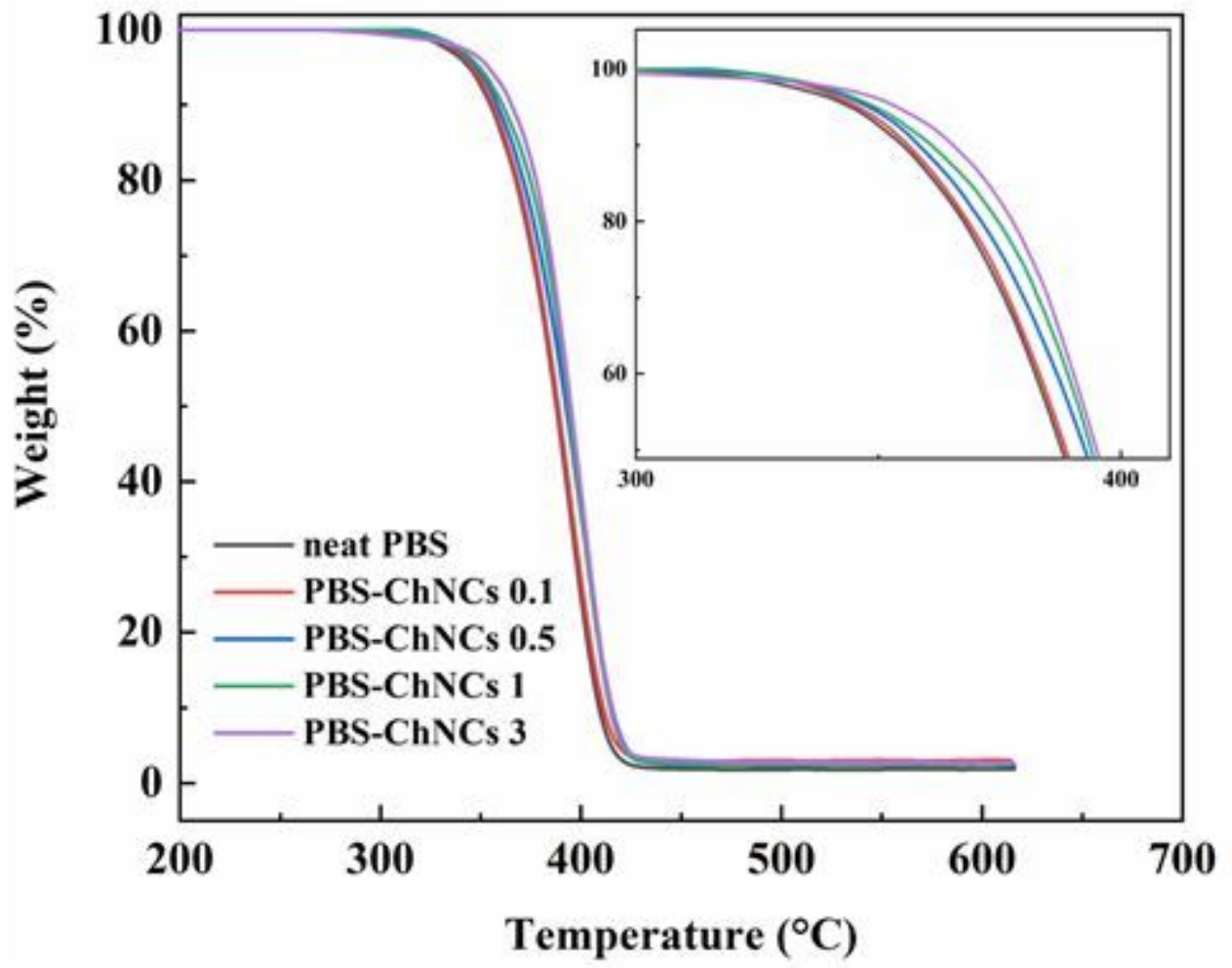

Figure 5

TGA curves of different PBS specimens.

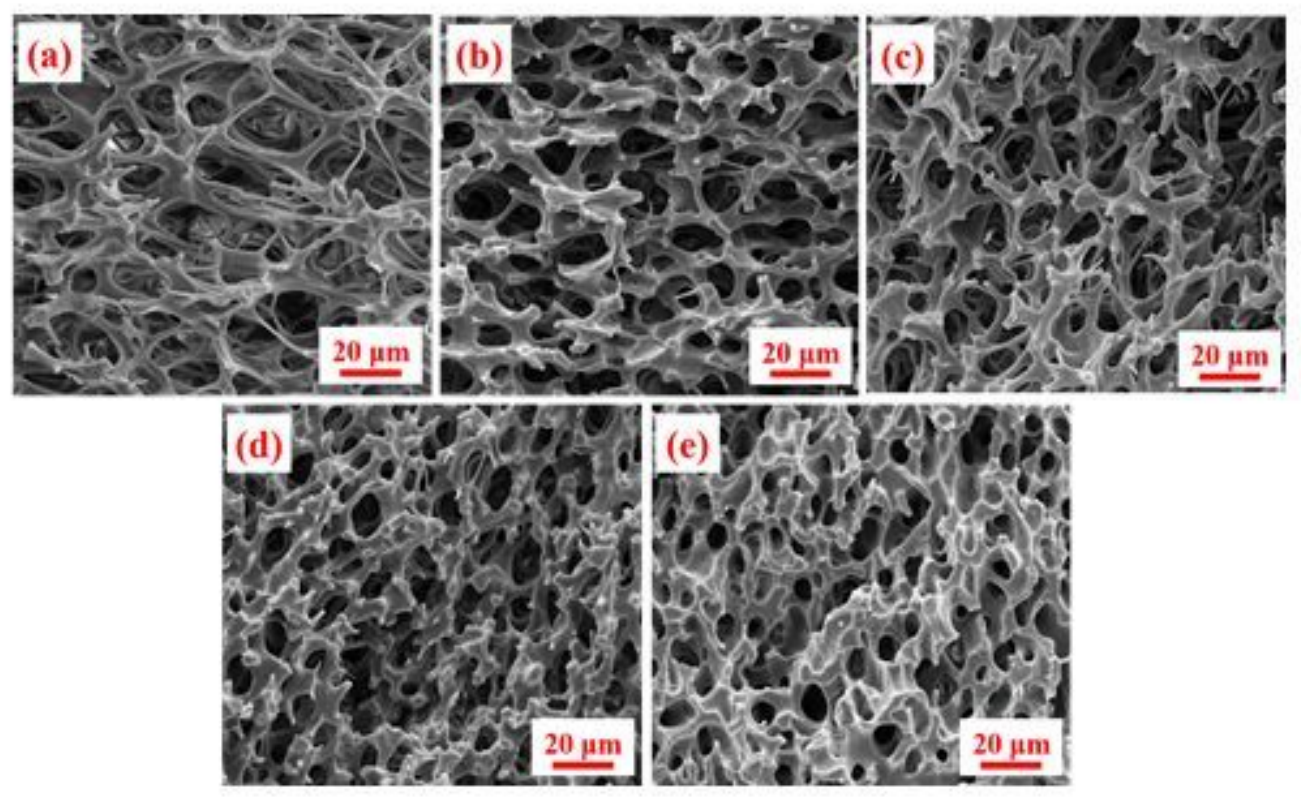

Figure 6

Porous morphologies of diverse PBS foams: (a) neat PBS foam; (b) PBS/ChNCs 0.1 foam; (c) PBS/ChNCs 0.5 foam; (d) PBS/ChNCs 1 foam; (e) PBS/ChNCs 3 foam; 

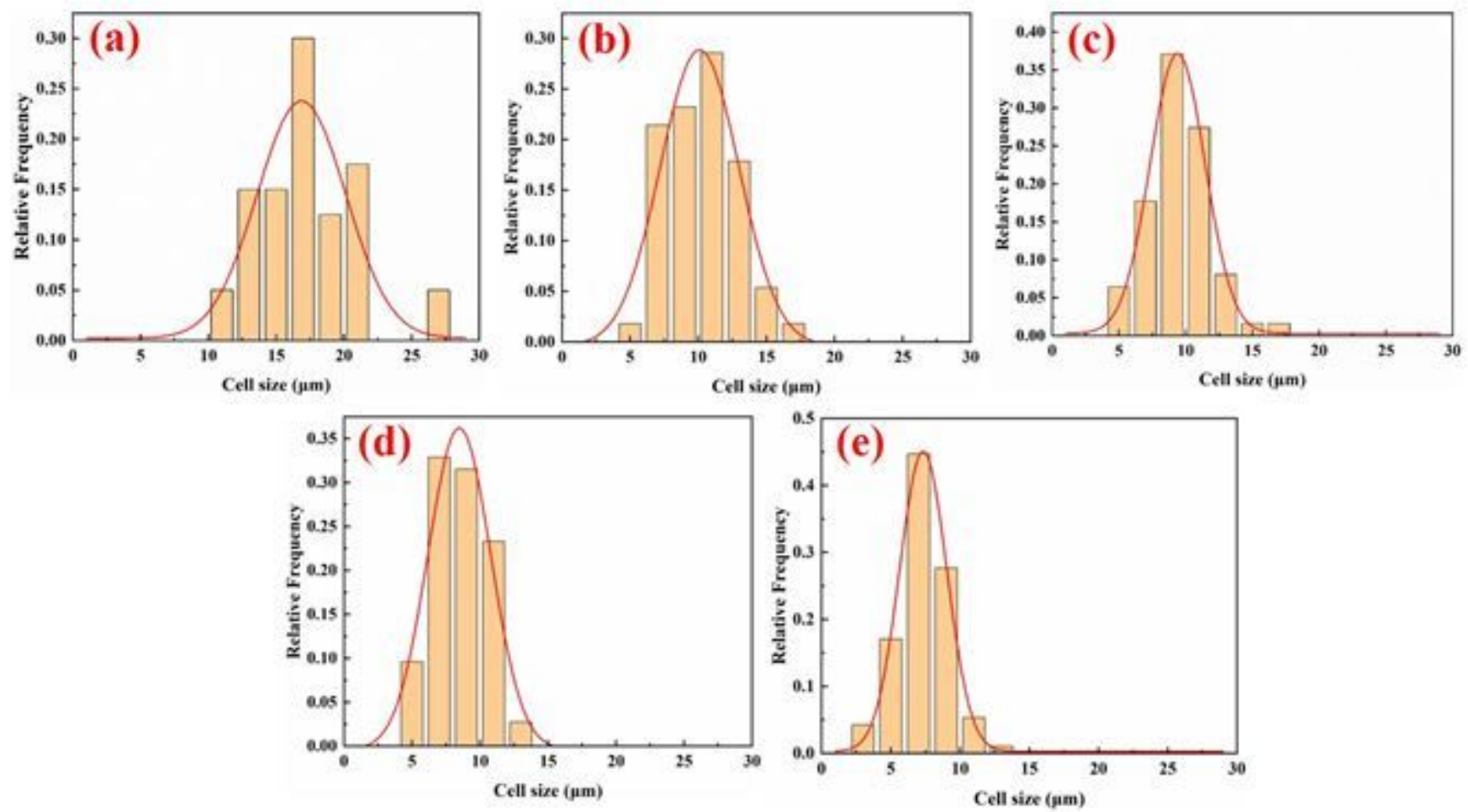

Figure 7

Pore size distribution of diverse PBS foams: (a) neat PBS foam; (b) PBS/ChNCs 0.1 foam; (c) PBS/ChNCs 0.5 foam; (d) PBS/ChNCs 1 foam; (e) PBS/ChNCs 3 foam; 


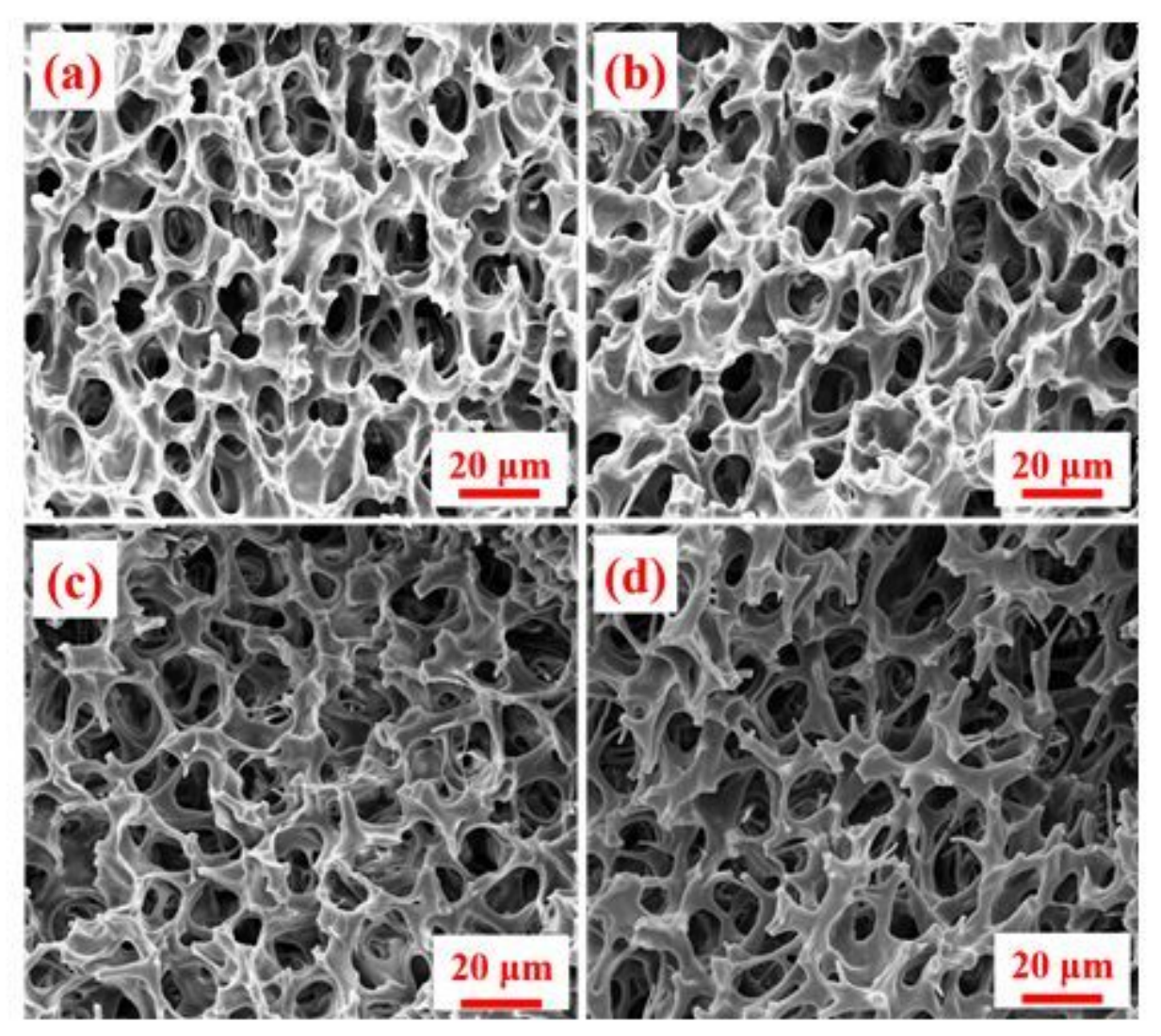

Figure 8

Porous morphologies of PBS-ChNCs 0.5 foams at different foaming temperatures: (a) $105^{\circ} \mathrm{C}$; (b) $107^{\circ} \mathrm{C}$; (c) $109^{\circ} \mathrm{C}$; (d) $111^{\circ} \mathrm{C}$; 

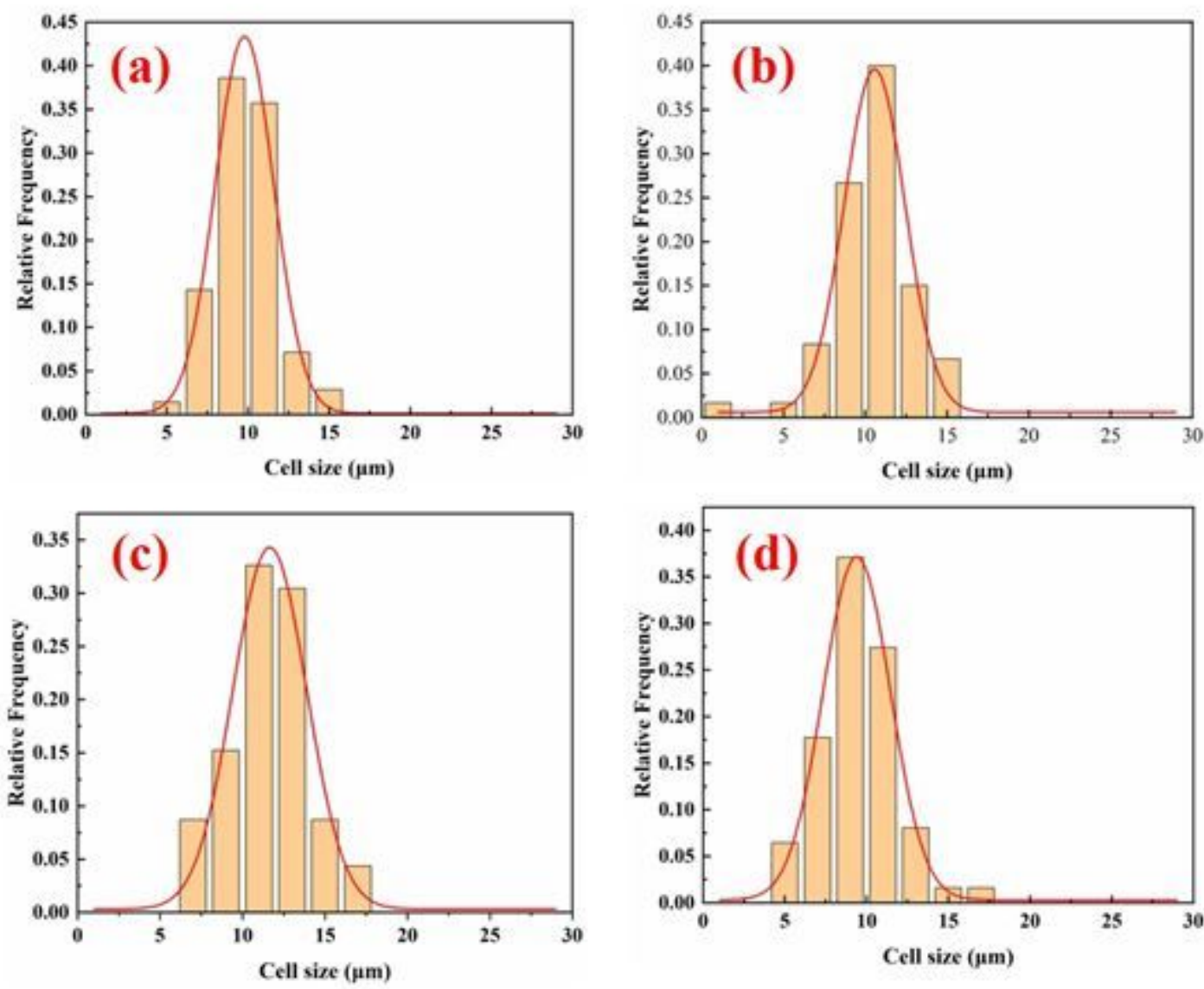

\section{Figure 9}

Pore size distribution of PBS-ChNCs 0.5 foams at diverse foaming temperatures: (a) $105^{\circ} \mathrm{C}$; (b) $107^{\circ} \mathrm{C}$; (c) $109^{\circ} \mathrm{C}$; (d) $111^{\circ} \mathrm{C}$;

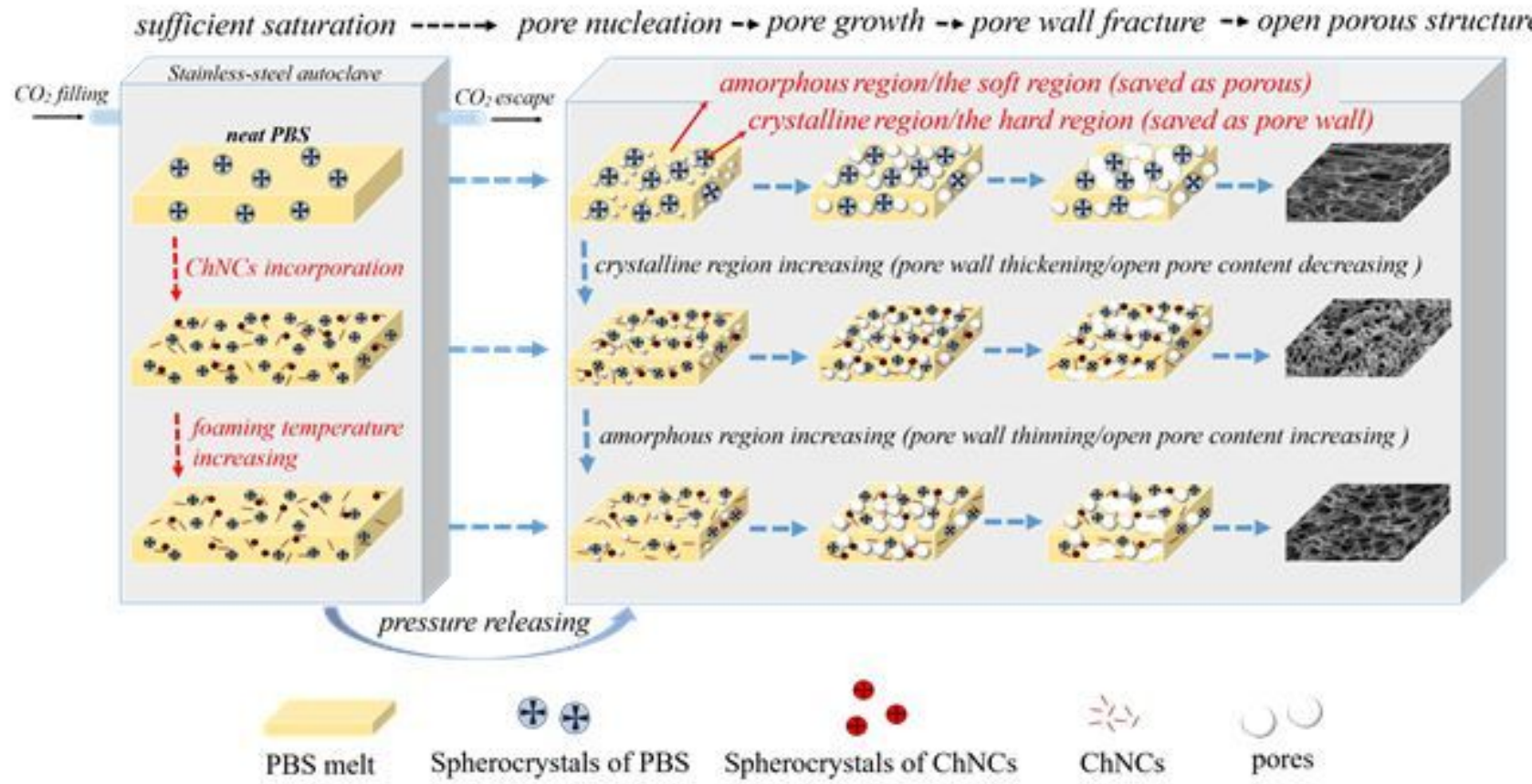


Figure 10

Schematic diagram for the open porous morphology evolution of diverse PBS foams.

\section{Supplementary Files}

This is a list of supplementary files associated with this preprint. Click to download.

- formula.docx 